\title{
DEFINIÇÃO DE ÁREA IMPACTADA E PARTICIPAÇÃO POPULAR NA RETOMADA DA ATIVIDADE MINERÁRIA APÓS DESASTRE AMBIENTAL
}

\author{
Leonardo Cordeiro de Gusmão* \\ Émilien Vilas Boas Reis**
}

\begin{abstract}
RESUMO: Por meio do método jurídico de raciocínio dedutivo com pesquisa qualitativa, descritiva e explicativa, mediante uma análise bibliográfica e documental, chega-se à conclusão de que em caso de desastre ambiental provocado por atividade de mineração capaz de causar significativo impacto ambiental, será possível o cancelamento ou a suspensão do empreendimento. Sua retomada dependerá de novos Estudos Prévios de Impactos Ambientais, os quais, em razão dos princípios da precaução e da cidadania, impõem o redimensionamento da noção de área impactada no intuito de abranger as áreas efetivamente atingidas, garantindo a participação popular informada da respectiva população.
\end{abstract}

Palavras-chaves: Mineração; Desastre Ambiental; Estudos de Impactos Ambientais; Definição de área impactada; Participação popular informada.

\section{DEFINITION OF IMPACTED AREA AND POPULAR PARTICIPATION AT RETURN OF THE MINING ACTIVITY AFTER ENVIRONMENTAL DISASTER}

\begin{abstract}
From the juridical method of deductive reasoning with quantitative, descriptive and explanatory research, it's concluded that in case of an environmental disaster provoked by mine activity capable to cause significant environmental impact, it will be possible to cancel or suspend the undertaking. Its resumption will depend of the new Preliminary Environmental Impact Studies, wich, due to the principles of precaution and citizenship, impose the reconstruction of the notion about impact área in order to cover the areas effectively affected, guaranteeing informed popular participation of the respective population.
\end{abstract}

Keywords: Mining; Environmental disaster; Environmental Impact Assessment; Definition of impacted área; Informed Popular Participation.

\footnotetext{
* Advogado. Mestrando em Direito Ambiental e Desenvolvimento Sustentável na Escola Superior Dom Helder Câmara. Pós-Graduado em Direito Tributário pela Fundação Getúlio Vargas. Graduado em Direito pela Faculdade de Direito do Vale do Rio Doce. Pesquisador do Grupo "Pensar a Cidade" - Dom Helder. E-mail: leonardodegusmao.adv@gmail.com

** Pós-doutorado em filosofia pela Universidade do Porto. Doutorado em filosofia pela Pontifícia Universidade Católica do Rio Grande do Sul. Mestrado em filosofia pela Pontifícia Universidade Católica do Rio Grande do Sul. Graduação em filosofia pela Universidade Federal de Minas Gerais. Professor adjunto da Escola Superior de Ensino Dom Helder Câmara, em nível de graduação e pós-graduação (mestrado). Coordenador do grupo "Pensar a cidade: seus aspectos ambientais, jurídicos e sociais" - Dom Helder. E-mail: mboasr@yahoo.com.br.
} 


\section{INTRODUÇÃO}

Pretende-se, a partir do método jurídico de raciocínio dedutivo com pesquisa qualitativa, descritiva e explicativa, mediante uma análise bibliográfica e documental, conceber qual deve ser a noção de área impactada antes da retomada de atividade minerária paralisada por suspensão ou cancelamento da licença ambiental - em razão de desastre ambiental, considerando a aplicação do princípio da precaução.

A mencionada análise é relevante porque a definição de área impactada é requisito exigido aos Estudos Prévios de Impactos Ambientais, os quais, nos termos da Constituição da República Federativa do Brasil de 1.988 (CRFB/88), são indispensáveis para que atividades potencialmente poluidoras, capazes de causar significativa degradação ambiental, possam exercer suas atividades.

Verificar-se-á, pois, se em caso de grave desastre ambiental que efetivamente afetar regiões não abrangidas pelos Estudos Prévios de Impactos Ambientais que possibilitaram o exercício de atividade de mineração, haverá a necessidade de redimensionar a noção de área impactada para incluí-las, enquadrando-as como áreas de influência do empreendimento.

Será averiguado, também, se na hipótese de paralisação da atividade determinada pelo Poder Público como consequência à degradação ambiental, sua retomada dependerá da realização de novos estudos ambientais e da participação informada da população, inclusive daquelas residentes nas localidades que inicialmente não foram consideradas como área de influência da atividade minerária.

\section{O ENTRELAÇAMENTO ENTRE ESTUDOS PRÉVIOS DE IMPACTOS AMBIENTAIS E LICENÇA AMBIENTALDE ATIVIDADE MINERÁRIA.}

O artigo $225^{3}$, caput, da Constituição da República Federativa do Brasil de 1.988 (CRFB/88) traz em seu bojo o direito fundamental ao meio ambiente ecologicamente equilibrado, considerando-o essencial à sadia qualidade de vida (BRASIL, 1988). De uma interpretação conjunta com o artigo $5^{04}$, inciso XXXV, da CRFB/88, se conclui que incumbe

\footnotetext{
${ }^{3}$ Art. 225. Todos têm direito ao meio ambiente ecologicamente equilibrado, bem de uso comum do povo e essencial à sadia qualidade de vida, impondo-se ao Poder Público e à coletividade o dever de defendê-lo e preserválo para as presentes e futuras gerações.

${ }^{4}$ XXXV - a lei não excluirá da apreciação do Poder Judiciário lesão ou ameaça a direito.
} 
ao Poder Público - poder executivo, legislativo e judiciário - e a toda coletividade o dever de preservá-lo e defendê-lo contra lesão ou ameaça de lesão.

Por sua vez, os incisos do $\S 1^{\circ}$ do artigo $225^{5}$ da CRFB/88 estabelecem obrigações específicas ao Poder Público, fundamentadas no princípio da precaução, destinadas a dar máxima eficácia à proteção ambiental (BRASIL, 1988). Já o $§ 2^{\circ}$ do art. $225^{6}$ da CRFB/88, que traz implícito o princípio do poluidor pagador, impõe ao explorador de recursos minerais a obrigação de internalizar os efeitos negativos dos impactos negativos causados por sua atividade, mediante a recuperação do meio ambiente degradado, enquanto que o $\S 3^{\mathbf{o} 7}$ estabelece uma ampla responsabilidade pelos danos causados - administrativa, penal e cível (BRASIL, 1988).

Dentre as medidas destinadas à precaução contra danos ambientais a serem adotadas pelo Poder Público, destaca-se para o presente trabalho aquela constante no inciso IV, $\S 1^{\circ}$, do artigo 225, consistente no dever de exigir apresentação de estudos prévios de impactos ambientais de empreendimentos que tenham a capacidade de causar significativa degradação ambiental.

Seguindo o norte constitucional, a lei 6.938/81, que estabelece a Política Nacional do Meio Ambiente, traz em seu artigo $9^{\circ 8} \mathrm{e}$ incisos, instrumentos destinados à proteção do meio

\footnotetext{
${ }^{5} \S 1^{\circ}$ Para assegurar a efetividade desse direito, incumbe ao Poder Público:

I - preservar e restaurar os processos ecológicos essenciais e prover o manejo ecológico das espécies e ecossistemas;

II - preservar a diversidade e a integridade do patrimônio genético do País e fiscalizar as entidades dedicadas à pesquisa e manipulação de material genético;

III - definir, em todas as unidades da Federação, espaços territoriais e seus componentes a serem especialmente protegidos, sendo a alteração e a supressão permitidas somente através de lei, vedada qualquer utilização que comprometa a integridade dos atributos que justifiquem sua proteção;

IV - exigir, na forma da lei, para instalação de obra ou atividade potencialmente causadora de significativa degradação do meio ambiente, estudo prévio de impacto ambiental, a que se dará publicidade;

$\mathrm{V}$ - controlar a produção, a comercialização e o emprego de técnicas, métodos e substâncias que comportem risco para a vida, a qualidade de vida e o meio ambiente;

VI - promover a educação ambiental em todos os níveis de ensino e a conscientização pública para a preservação do meio ambiente;

VII - proteger a fauna e a flora, vedadas, na forma da lei, as práticas que coloquem em risco sua função ecológica, provoquem a extinção de espécies ou submetam os animais a crueldade.

$6 \S 2^{\circ}$ Aquele que explorar recursos minerais fica obrigado a recuperar o meio ambiente degradado, de acordo com solução técnica exigida pelo órgão público competente, na forma da lei.

${ }^{7} \S 3^{\circ}$ As condutas e atividades consideradas lesivas ao meio ambiente sujeitarão os infratores, pessoas físicas ou jurídicas, a sanções penais e administrativas, independentemente da obrigação de reparar os danos causados.

${ }^{8}$ Art $9^{\circ}$ - São instrumentos da Política Nacional do Meio Ambiente:

I - o estabelecimento de padrões de qualidade ambiental;

II - o zoneamento ambiental;

III - a avaliação de impactos ambientais;

IV - o licenciamento e a revisão de atividades efetiva ou potencialmente poluidoras;
} 
ambiente ecologicamente equilibrado, dentre os quais se encontram a avaliação de impactos ambientais e o licenciamento ambiental de atividades efetiva ou potencialmente poluidoras, que são aquelas causadoras de significativo impacto ambiental (BRASIL, 1981).

De acordo com o artigo $1^{\text {o9 }}$ da Resolução CONAMA 001/86, considera-se impacto ambiental as alterações consequentes de atividades humanas que incidam direta ou indiretamente sob as propriedades essenciais do meio ambiente - físicas, químicas e biológicas -, afetando-o de forma a colocar em risco a saúde, segurança e o bem-estar da população (BRASIL, 1986).

O termo "significativo", por sua vez, compreende uma degradação de grande repercussão negativa que compromete o equilíbrio ambiental. Sua definição precisa será incumbência do Poder Público em face da situação concreta, após considerar a sensibilidade da área sob a qual se promoverá o empreendimento, adotando-se os critérios técnicos necessários à obtenção de todas as informações pertinentes à avaliação do impacto (BECHARA, 2013, 116).

\footnotetext{
$\mathrm{V}$ - os incentivos à produção e instalação de equipamentos e a criação ou absorção de tecnologia, voltados para a melhoria da qualidade ambiental;

VI - a criação de espaços territoriais especialmente protegidos pelo Poder Público federal, estadual e municipal, tais como áreas de proteção ambiental, de relevante interesse ecológico e reservas extrativistas;

VII - o sistema nacional de informações sobre o meio ambiente;

VIII - o Cadastro Técnico Federal de Atividades e Instrumentos de Defesa Ambiental;

IX - as penalidades disciplinares ou compensatórias ao não cumprimento das medidas necessárias à preservação ou correção da degradação ambiental.

X - a instituição do Relatório de Qualidade do Meio Ambiente, a ser divulgado anualmente pelo Instituto Brasileiro do Meio Ambiente e Recursos Naturais Renováveis - IBAMA;

XI - a garantia da prestação de informações relativas ao Meio Ambiente, obrigando-se o Poder Público a produzilas, quando inexistentes;

XII - o Cadastro Técnico Federal de atividades potencialmente poluidoras e/ou utilizadoras dos recursos ambientais.

XIII - instrumentos econômicos, como concessão florestal, servidão ambiental, seguro ambiental e outros.

${ }^{9}$ Artigo $1^{\circ}$ - Para efeito desta Resolução, considera-se impacto ambiental qualquer alteração das propriedades físicas, químicas e biológicas do meio ambiente, causada por qualquer forma de matéria ou energia resultante das atividades humanas que, direta ou indiretamente, afetam:

I - a saúde, a segurança e o bem-estar da população;

II - as atividades sociais e econômicas;

III - a biota;

IV - as condições estéticas e sanitárias do meio ambiente;

$\mathrm{V}$ - a qualidade dos recursos ambientais.
} 
No que diz respeito à mineração, caso se enquadre nos critérios estabelecidos pelo Anexo VIII ${ }^{10}$ da Lei 6.938/81, Anexo $1^{11}$ da Resolução CONAMA 237/97 e/ou art. $2^{\text {o12 }}$, IX, da Resolução CONAMA 001/86, será considerada atividade potencialmente poluidora, exigindo a correspondente realização dos estudos de avaliação de impactos ambientais e a obtenção da licença ambiental.

De acordo com o artigo $1^{013}$, incisos I, II e III da Resolução CONAMA 237/97, o licenciamento ambiental é procedimento administrativo por meio do qual o órgão ambiental competente estabelecerá as condições necessárias para a concessão das licenças ambientais ato administrativo - ao empreendedor. Diz ainda que os estudos ambientais se destinam à delimitação de aspectos ambientais relacionados à "localização, instalação, operação e ampliação" do empreendimento (BRASIL, 1997).

Por sua vez, o artigo $8^{\text {o14 }}$ da Resolução 237/97 estabelece três tipos de licença ambiental a serem obtidas pelo empreendedor: a) licença prévia, que se destina a aprovar a

10 - pesquisa mineral com guia de utilização; lavra a céu aberto, inclusive de aluvião, com ou sem beneficiamento; lavra subterrânea com ou sem beneficiamento, lavra garimpeira, perfuração de poços e produção de petróleo e gás natural.

${ }^{11}$ Extração e tratamento de minerais

- pesquisa mineral com guia de utilização

- lavra a céu aberto, inclusive de aluvião, com ou sem beneficiamento

- lavra subterrânea com ou sem beneficiamento

- lavra garimpeira

- perfuração de poços e produção de petróleo e gás natural

${ }^{12}$ Artigo $2^{\circ}$ - Dependerá de elaboração de estudo de impacto ambiental e respectivo relatório de impacto ambiental - RIMA, a serem submetidos à aprovação do órgão estadual competente, e do IBAMA e1n caráter supletivo, o licenciamento de atividades modificadoras do meio ambiente, tais como:

IX - Extração de minério, inclusive os da classe II, definidas no Código de Mineração;

${ }^{13}$ Art. $1^{\circ}$ - Para efeito desta Resolução são adotadas as seguintes definições:

I - Licenciamento Ambiental: procedimento administrativo pelo qual o órgão ambiental competente licencia a localização, instalação, ampliação e a operação de empreendimentos e atividades utilizadoras de recursos ambientais , consideradas efetiva ou potencialmente poluidoras ou daquelas que, sob qualquer forma, possam causar degradação ambiental, considerando as disposições legais e regulamentares e as normas técnicas aplicáveis ao caso.

II - Licença Ambiental: ato administrativo pelo qual o órgão ambiental competente, estabelece as condições, restrições e medidas de controle ambiental que deverão ser obedecidas pelo empreendedor, pessoa física ou jurídica, para localizar, instalar, ampliar e operar empreendimentos ou atividades utilizadoras dos recursos ambientais consideradas efetiva ou potencialmente poluidoras ou aquelas que, sob qualquer forma, possam causar degradação ambiental.

III - Estudos Ambientais: são todos e quaisquer estudos relativos aos aspectos ambientais relacionados à localização, instalação, operação e ampliação de uma atividade ou empreendimento, apresentado como subsídio para a análise da licença requerida, tais como: relatório ambiental, plano e projeto de controle ambiental, relatório ambiental preliminar, diagnóstico ambiental, plano de manejo, plano de recuperação de área degradada e análise preliminar de risco.

${ }^{14}$ Art. $8^{\circ}$ - O Poder Público, no exercício de sua competência de controle, expedirá as seguintes licenças:

I - Licença Prévia (LP) - concedida na fase preliminar do planejamento do empreendimento ou atividade aprovando sua localização e concepção, atestando a viabilidade ambiental e estabelecendo os requisitos básicos e condicionantes a serem atendidos nas próximas fases de sua implementação; 
localização do projeto e à verificação de sua viabilidade ambiental, estabelecendo condicionantes a serem cumpridas; b) licença de instalação, cuja finalidade consiste na autorização para o empreendedor instalar o empreendimento após a constatação de que ele cumpriu com as exigências feitas na licença prévia; c) licença de operação, na qual se autorizará a execução da atividade empresarial após se constatar o efetivo cumprimento de todas as exigências feitas pelo órgão ambiental nas etapas anteriores (BRASIL, 1997).

Importante ressaltar a natureza jurídica da licença ambiental, haja vista que tal característica servirá para delimitar a atuação do órgão licenciante no processo de licenciamento ao analisar os estudos prévios de impactos ambientais. De acordo com Érika Bechara (BECHARA, 2013, p. 132), a licença ambiental é ato administrativo de natureza híbrida, de modo que diante dos resultados dos estudos ambientais, caso existam diferentes opções legal e ambientalmente viáveis para o desenvolvimento da atividade, o empreendedor terá o direito a desenvolver uma delas (característica de ato vinculado). Qual delas, contudo, o órgão ambiental, dentro de sua discricionariedade técnica, deverá fazer sua escolha (característica de ato discricionário).

Dessa forma, uma vez demonstrado o preenchimento dos requisitos necessários à viabilidade socioambiental do empreendimento de mineração, deverá o órgão ambiental conceder a respectiva licença ambiental. Uma vez obtida licença de operação, dar-se-á início à atividade minerária.

Realizadas as considerações necessárias acerca do vínculo entre Estudos Prévios de Impactos Ambientais e o procedimento do licenciamento ambiental, bem como a delimitação da natureza jurídica da licença ambiental e o enquadramento da atividade minerária como sendo de significativo impacto ambiental, passa-se à definição do que se chama por "área de influência ou área impactada".

II - Licença de Instalação (LI) - autoriza a instalação do empreendimento ou atividade de acordo com as especificações constantes dos planos, programas e projetos aprovados, incluindo as medidas de controle ambiental e demais condicionantes, da qual constituem motivo determinante;

III - Licença de Operação (LO) - autoriza a operação da atividade ou empreendimento, após a verificação do efetivo cumprimento do que consta das licenças anteriores, com as medidas de controle ambiental e condicionantes determinados para a operação. 


\section{DEFINIÇÃO DE ÁREA IMPACTADA.}

Conforme visto no tópico anterior, em se tratando de atividade de significativo impacto ambiental, como a mineração, deverá o empreendedor apresentar Estudos Prévios de Impactos Ambientais destinados à verificação de sua viabilidade socioambiental. Nesse contexto tornase relevante destacar as diretrizes que deverão ser observadas em tais estudos, as quais estão previstas no artigo $5^{\circ}$ da Resolução CONAMA 001/86:

\footnotetext{
Artigo $5^{\circ}$ - O estudo de impacto ambiental, além de atender à legislação, em especial os princípios e objetivos expressos na Lei de Política Nacional do Meio Ambiente, obedecerá às seguintes diretrizes gerais:

I - Contemplar todas as alternativas tecnológicas e de localização de projeto, confrontando-as com a hipótese de não execução do projeto;

II - Identificar e avaliar sistematicamente os impactos ambientais gerados nas fases de implantação e operação da atividade ;

III - Definir os limites da área geográfica a ser direta ou indiretamente afetada pelos impactos, denominada área de influência do projeto, considerando, em todos os casos, a bacia hidrográfica na qual se localiza;

IV - Considerar os planos e programas governamentais, propostos e em implantação na área de influência do projeto, e sua compatibilidade. (BRASIL, 1986) (grifos nossos)
}

Apreende-se, assim, que além de observar a legislação ambiental, nos Estudos Prévios de Impactos Ambientais deve-se abordar a área geográfica de influência do projeto, que será aquela afetada direta ou indiretamente pelos impactos, sempre considerando a bacia hidrográfica que pode ser atingida. De posse dessa informação, deverão ser apresentadas alternativas tecnológicas e de localização do projeto, analisando as repercussões socioambientais resultantes e sua viabilidade de execução.

Nesse contexto, ao tratar do artigo $5^{\circ}$ da Resolução CONAMA 001/86 e da correspondente definição de área de influência, isto é, ao analisar a tarefa de delimitação da área sujeita aos significativos impactos ambientais, Paulo Affonso Leme Machado afirma que:

A definição da área geográfica a ser estudada não fica ao arbítrio do órgão público ambiental, do proponente do projeto ou da equipe multidisciplinar. A possibilidade de se registrarem impactos significativos, que vai delimitar a área chamada de influência do projeto. A resolução, contudo, apontou uma referência geográfica inarredável do estudo: a bacia hidrográfica na qual se situará o projeto (MACHADO, 2016, p. 276). (grifos nossos)

Sob tal perspectiva a Norma Reguladora da Mineração no 21 (NRM-21) emitida pelo Departamento Nacional de Produção Mineral (DNPM) através da Portaria 237/2001, definiu área impactada como sendo "toda área com diversos graus de alteração tanto dos fatores 
bióticos quanto abióticos causados pela atividade de mineração" (BRASIL, 2001). Em Minas Gerais, dispõe no mesmo sentido o artigo $1^{\circ}$, inciso I, da Deliberação Normativa 127/2008 ${ }^{15}$, expedida pelo Conselho Estadual de Política Ambiental (COPAM), ao regulamentar a questão do fechamento de mina (MINAS GERAIS, 2008).

Ao prosseguir com a regulamentação acerca do conteúdo dos Estudos Prévios de Impactos Ambientais, o artigo $6^{\circ}$ da Resolução CONAMA 001/86 faz uma disposição detalhada, prevendo informações indispensáveis, além de obrigar o empreendedor a elaborar um programa de acompanhamento dos impactos ambientais:

\footnotetext{
Artigo $6^{\circ}$ - O estudo de impacto ambiental desenvolverá, no mínimo, as seguintes atividades técnicas:

[...]

II - Análise dos impactos ambientais do projeto e de suas alternativas, através de identificação, previsão da magnitude e interpretação da importância dos prováveis impactos relevantes, discriminando: os impactos positivos e negativos (benéficos e adversos), diretos e indiretos, imediatos e a médio e longo prazos, temporários e permanentes; seu grau de reversibilidade; suas propriedades cumulativas e sinérgicas; a distribuição dos ônus e benefícios sociais. $[\ldots]$

IV - Elaboração do programa de acompanhamento e monitoramento dos impactos positivos e negativos, indicando os fatores e parâmetros a serem considerados. (BRASIL, 1986) (grifos nossos)
}

Pode-se dizer, assim, que os Estudos Prévios de Impactos Ambientais e a licença ambiental são instrumentos que se complementam, previstos pela Política Nacional do Meio Ambiente. Fica claro, ademais, que os estudos prévios de impactos ambientais e a formulação do respectivo relatório deverão considerar toda a área geográfica capaz de sofrer impactos ambientais significativos em razão do exercício da mineração, em especial a bacia hidrográfica que pode ser afetada. As conclusões obtidas servirão para subsidiar a atuação do órgão licenciante, no que tange à concessão ou não da licença ambiental.

Realizadas as ponderações necessárias acerca da definição da área de influência/área impactada de empreendimento capaz de causar significativos impactos ambientais, além de se expor a íntima relação entre os estudos prévios de impactos ambientais e a licença ambiental, faz-se necessário, agora, tratar da participação popular em tais procedimentos.

\footnotetext{
${ }^{15}$ Art. $1^{\circ}$ Para fins de aplicação desta Deliberação Normativa ficam estabelecidas as seguintes definições: I - Área impactada: toda área com diversos graus de alteração, tanto dos fatores bióticos quanto abióticos causados pela atividade de mineração.
} 


\section{ESTUdOS PRÉVIOS DE IMPACTOS AMBIENTAIS E PARTICIPAÇÃO DA POPULAÇÃO DA ÁREA IMPACTADA.}

Constatou-se neste trabalho que para que seja viável a operacionalização de atividade de mineração no Brasil, deverá o minerador, primeiramente, apresentar Estudos Prévios de Impactos Ambientais e seu respectivo Relatório de Impactos Ambientais (EPIA/RIMA). Neles, delimitar-se-á toda a área geográfica de influência do projeto, isto é, será definida toda extensão dos impactos ambientais diretos e indiretos, sempre considerando a bacia hidrográfica na qual se localiza o empreendimento.

Agora, torna-se relevante destacar que além do artigo 225 da CRFB/88 definir o meio ambiente como bem de uso comum de todos (bem difuso), cabendo ao poder público e a toda coletividade a obrigação de protegê-lo e defendê-lo, também classifica o meio ambiente ecologicamente equilibrado como direito fundamental, considerando-o essencial à sadia qualidade de vida, sendo sua observância, portanto, indispensável ao alcance da dignidade da pessoa humana.

Sendo o meio ambiente ecologicamente equilibrado um direito fundamental garantido aos indivíduos, característica esta que impõe à coletividade o dever de protegê-lo contra agressões, deve-se oportunizar a participação popular informada durante a realização dos Estudos Prévios de Impactos Ambientais, uma vez que as respectivas conclusões subsidiarão o órgão ambiental na decisão acerca do licenciamento de atividade causadora de impactos significativos, tal como a mineração.

Vale lembrar que o artigo $1^{\circ}$, caput, da CRFB/88 consolidou o Estado Democrático de Direito e, sob tal perspectiva, convém ressaltar os ensinamentos de José Adércio Leite Sampaio, segundo o qual “o princípio do Estado Democrático de Direito não se consola apenas com a figura da representação política formal, exigindo simultaneamente a participação popular e a colaboração judicial responsável nos exercícios de concretização dos direitos fundamentais." (SAMPAIO, 2003, p. 93). Significa dizer que a atuação cidadã não se limita ao voto e às deliberações dos representantes eleitos, exigindo-se a inserção dos indivíduos e da coletividade na tomada de decisões relevantes que afetem seus interesses

As informações contidas nos Estudos Prévios de Impactos Ambientais e em seu respectivo relatório, às quais se dará publicidade na forma do artigo $225, \S 1^{\circ}$, incisos IV e VI, da CRFB/88, terão serventia também para formação de uma opinião pública qualificada, 
possibilitando a realização de comentários pertinentes, além de uma participação eficiente durante eventual convocação de audiência pública. Mostra-se útil, nesse sentido, a disposição contida no artigo 11, § $2^{\circ}$, da Resolução CONAMA 001/86:

\begin{abstract}
$\S 2^{\circ}$ - Ao determinar a execução do estudo de impacto ambiental e apresentação do RIMA, o estadual competente ou o IBAMA ou, quando couber o Município, determinará o prazo para recebimento dos comentários a serem feitos pelos órgãos públicos e demais interessados e, sempre que julgar necessário, promoverá a realização de audiência pública para informação sobre o projeto e seus impactos ambientais e discussão do RIMA (BRASIL, 1986) (grifo nosso)
\end{abstract}

No caso da audiência pública, os artigos $1^{\text {o e }} 2^{\text {ol6 }}$ da Resolução CONAMA 009/1986 dizem que sua realização será obrigatória quando requerida "por entidade civil, pelo Ministério Público, ou por 50 ou mais cidadãos" (BRASIL, 1986). Em relação à sua finalidade, na audiência pública serão expostos todos os aspectos constantes na análise dos impactos ambientais, sendo também a ocasião adequada para esclarecer dúvidas e registrar críticas e sugestões formuladas pelos interessados presentes, as quais devem ser consideradas pelo órgão público, sob pena de invalidade e ilegitimidade da licença ambiental posteriormente concedida.

Diante da necessidade dos Estudos Prévios de Impactos Ambientais serem pautados na concepção de área de influência do projeto, ou seja, em razão da imprescindibilidade em se especificar todas as áreas sujeitas aos impactos ambientais negativos diretos ou indiretos, imediatos ou a médio e longo prazo, decorrentes do empreendimento, a publicação do edital do EPIA/RIMA deverá abranger todas as regiões passíveis de sofrer tais impactos, possibilitando que os respectivos cidadãos participem e convoquem audiência pública.

Importante trazer à tona, nesse momento, algumas lições proporcionadas por Romeu Thomé e José Cláudio Junqueira Ribeiro, no que diz respeito à participação dos indivíduos pertencentes às comunidades afetadas pelo empreendimento, durante o processo de avaliação dos impactos ambientais:

The main objective of the public participation is to insure the exercise of citizenship and democracy in the environmental impact assessment process, a time when the different actors who are involved and possibly directly or indirectly affected by a project or an activity should have full access to the information related to its positive

\footnotetext{
${ }^{16}$ Art. $1^{\circ}$ - A Audiência Pública referida na RESOLUÇÃO/conama/N. ${ }^{\circ}$ 001/86, tem por finalidade expor aos interessados o conteúdo do produto em análise e do seu referido RIMA, dirimindo dúvidas e recolhendo dos presentes as críticas e sugestões a respeito.

Art. $2^{\circ}$ - Sempre que julgar necessário, ou quando for solicitado por entidade civil, pelo Ministério Público, ou por 50 (cinqüenta) ou mais cidadãos, o Órgão de Meio Ambiente promoverá a realização de audiência pública.
} 
and negative social-environmental impact so that they can inform the relevant public agencies of their opinion ${ }^{17}$ (THOMÉ, RIBEIRO, 2015, p. 08).

A participação popular informada é um direito garantido pelo ordenamento jurídico pátrio e também está previsto em documentos internacionais. Na Conferência das Nações Unidas sobre o Meio Ambiente (Rio-92), inclusive, foi dada a necessária importância a sua efetivação nas hipóteses de instalação de empreendimento potencialmente ou efetivamente degradante, tal como a mineração:

\begin{abstract}
Princípio 10 A melhor maneira de tratar as questões ambientais é assegurar a participação, no nível apropriado, de todos os cidadãos interessados. No nível nacional, cada indivíduo terá acesso adequado às informações relativas ao meio ambiente de que disponham as autoridades públicas, inclusive informações acerca de materiais e atividades perigosas em suas comunidades, bem como a oportunidade de participar dos processos decisórios. Os Estados irão facilitar e estimular a conscientização e a participação popular, colocando as informações à disposição de todos. Será proporcionado o acesso efetivo a mecanismos judiciais e administrativos, inclusive no que se refere à compensação e reparação de danos. (ONU, 1992)
\end{abstract}

Nesse contexto, ao realizar a definição de área impactada, os Estudos Prévios de Impactos Ambientais deverão delimitar quais serão as comunidades afetadas, possibilitando que seus cidadãos exerçam seu direito de participação e, de tal forma, estejam aptos a se manifestar de forma consciente acerca de questões relevantes à sua autodeterminação e aos interesses das futuras gerações. Convém frisar, por se mostrar oportuno, as palavras de Paulo Affonso Leme Machado:

O EPIA somente poderá conseguir êxito em sua missão de prevenção do impacto ambiental se a Administração Pública mostrar-se aberta à participação do público nesse procedimento.

Além dos mecanismos legais que permitam a participação, há de ser mantido pelos servidores públicos - responsáveis pela análise do Estudo de Impacto - a preocupação em conhecer e valorizar os argumentos da população envolvida e atingida pelos possíveis efeitos do projeto - esse posicionamento administrativo irá dimensionar o sucesso ou o fracasso do EPIA. (MACHADO, 2016, p. 310)

\footnotetext{
${ }^{17} \mathrm{O}$ objetivo nuclear da participação pública é assegurar o exercício da cidadania e da democracia no processo de avaliação de impacto ambiental, momento em que os diversos atores envolvidos e potencialmente afetados, direta ou indiretamente, por projeto ou atividade, devem ter amplo acesso às informações relacionadas ao seu impacto socioambiental, tanto positivos quanto negativos, para que possam externar sua opinião aos órgãos públicos competentes.
} 
Além da possibilidade de atuar na esfera administrativa para expor suas opiniões e questionamentos acerca das conclusões dos Estudos Prévios de Impactos Ambientais de atividade causadora de significativos impactos ambientais, também será possível ao cidadão, com fulcro no artigo $5^{\circ 18}$, inciso LXXIII, da CRFB/88, ajuizar ação popular ambiental visando impugnar algum ato ou omissão referente ao licenciamento, caso se configure como lesivo ao meio ambiente ecologicamente equilibrado, no intuito de promover a adequada prevenção contra danos (BRASIL, 1988). Para tanto, poderá valer-se das informações fornecidas pelos estudos realizados.

Assim, chega-se à conclusão que uma vez delimitada a área de influência - da área impactada - do projeto empresarial objeto dos Estudos Prévios de Impactos Ambientais, devese oportunizar que os cidadãos interessados se manifestem e convoquem audiência pública, sendo que suas críticas e sugestões não podem ser simplesmente desconsideradas pelo órgão ambiental, sob pena do projeto licenciante se configurar como ilegítimo e inválido.

Diante da linha de raciocínio exposta, convém mencionar mais uma vez as palavras de Romeu Thomé e José Cláudio Junqueira Ribeiro:

\begin{abstract}
As we can see, the active participation of people in the environmental impact assessment investigation process can legitimate the decision made by the public manager as people who were directly affected by the activity that is being investigated are represented during the entire environmental evaluation, taking this environment impact investigation process into the category of essential mechanism for the Democratic and Social-Environmental Rule of Law. The perspectives of different groups provide useful elements to base decision making, especially when some values or factors cannot be easily quantified ${ }^{19}$. (THOMÉ, RIBEIRO, 2015, p. 16).
\end{abstract}

Ante o raciocínio exposto, analisar-se-ão no próximo tópico as repercussões decorrentes de desastres ambientais envolvendo atividade de mineração, no que diz respeito à retomada de atividade paralisada por determinação do órgão ambiental, expondo a necessidade de redefinição da área impactada para considerar toda a região que foi comprovadamente

\footnotetext{
${ }^{18}$ LXXIII - qualquer cidadão é parte legítima para propor ação popular que vise a anular ato lesivo ao patrimônio público ou de entidade de que o Estado participe, à moralidade administrativa, ao meio ambiente e ao patrimônio histórico e cultural, ficando o autor, salvo comprovada má-fé, isento de custas judiciais e do ônus da sucumbência. ${ }^{19}$ Como se percebe, a luzes claras, a participação ativa dos indivíduos no processo de investigação da avaliação de impactos ambientais tem o condão de legitimar a decisão do administrador público, na medida em que as pessoas diretamente afetadas pela atividade investigada encontram-se representadas em toda a extensão da avaliação ambiental, alçando esse processo de investigação de impactos ao meio ambiente à categoria de mecanismo imprescindível ao Estado Democrático e Socioambiental de Direito. Perspectivas de diversos grupos de interesse fornecem elementos úteis para subsidiar a tomada de decisões, especialmente quando alguns valores ou fatores não podem ser facilmente quantificados.
} 
afetada pela degradação ambiental, garantindo-se a participação da respectiva população como condição para a legitimidade e validade do empreendimento.

\section{O PRINCÍPIO DA PRECAUÇÃO E A DEFINIÇÃO DE ÁREA IMPACTADA NA RETOMADA DA ATIVIDADE DE MINERAÇÃO APÓS DESASTRE AMBIENTAL.}

Como já bem debatido neste trabalho, a obtenção de licença ambiental de atividade minerária, devido aos significativos impactos ambientais consequentes, dependerá da realização de Estudos Prévios de Impactos Ambientais e da apresentação do respectivo relatório, sobre os quais se dará publicidade e a consequente oportunidade de manifestação popular informada, inclusive por meio de audiência pública, caso esta seja adequadamente convocada.

No que diz respeito à mineração, há de se destacar a grande periculosidade das barragens de contenção de rejeito de minério, cuja segurança, segundo o artigo $2^{\circ 20}$, III, da Lei 12.334/10, é condição indispensável à preservação da saúde, da vida, da propriedade e do meio ambiente ecologicamente equilibrado (BRASIL, 2010). Contudo, apesar do alerta feito pelo legislador, desastres ambientais envolvendo barragens não são incomuns no Brasil, causando graves impactos socioambientais, conforme frisado por André de Paiva Toledo, José Cláudio Junqueira Ribeiro e Romeu Thomé:

No Brasil, as ocorrências envolvendo barragens de contenção de rejeitos de mineração e seus consequentes impactos socioambientais já vêm despertando, há algum tempo, a atenção da sociedade e de pesquisadores para a necessidade de se reavaliar práticas de gestão, segurança, planejamento e inovação tecnológica para estas estruturas. (TOLEDO, RIBEIRO, THOMÉ, 2016, p. 139)

Diante dos riscos inerentes à atividade minerária, não apenas em decorrência de suas barragens - cujo perigo é reconhecido legalmente -, faz-se necessário o máximo de cuidado e a obtenção das informações pertinentes visando evitar a ocorrência ou repetição de desastres ambientais.

Uma vez ocorrido o desastre ambiental em razão da atividade minerária, seja em razão da gravidade dos danos socioambientais ou devido à debilidade das informações prestadas nos

\footnotetext{
${ }^{20}$ Art. $2^{\circ}$ Para os efeitos desta Lei, são estabelecidas as seguintes definições:

III - segurança de barragem: condição que vise a manter a sua integridade estrutural e operacional e a preservação da vida, da saúde, da propriedade e do meio ambiente.
} 
Estudos Prévios de Impactos Ambientais, será possível que o órgão licenciante suspenda ou cancele a licença ambiental concedida à mineradora, conforme especificado pelo artigo 19 da Resolução CONAMA 237/97:

\footnotetext{
Art. 19 - O órgão ambiental competente, mediante decisão motivada, poderá modificar os condicionantes e as medidas de controle e adequação, suspender ou cancelar uma licença expedida, quando ocorrer:

I - Violação ou inadequação de quaisquer condicionantes ou normas legais.

II - Omissão ou falsa descrição de informações relevantes que subsidiaram a expedição da licença.

III - superveniência de graves riscos ambientais e de saúde. (BRASIL, 1997)
}

Caso se determine a suspensão ou o cancelamento da licença, ficará a mineradora impedida de operar, devendo o órgão ambiental promover a revisão da licença ambiental nos termos do artigo $9^{\circ}$, IV, da lei 6.938/81 (BRASIL, 1981). De acordo com Talden Farias, a revisão consiste na "perda da validade no todo ou em parte, temporária ou permanentemente, da licença ainda no seu prazo de vigência” (FARIAS, 2013, p. 148).

Quando a paralisação da atividade minerária for temporária será caso de suspensão, enquanto que se permanente, terá o órgão ambiental optado pelo cancelamento da licença. Em todo o caso a preocupação será com os riscos socioambientais decorrentes do empreendimento. Em se tratando da suspensão, poderá a mineradora voltar a operar se demonstrar que adotou medidas eficazes necessárias à regularização do empreendimento, de modo a impedir a concretização dos riscos socioambientais.

Na hipótese de cancelamento, por sua vez, embora seja incomum o retorno da atividade minerária pelo mesmo empreendedor e na mesma localidade, não há impedimento legal. Para tanto, será necessário recomeçar do zero o processo de licenciamento, inclusive com apresentação dos Estudos Prévios de Impactos Ambientais e seu relatório, oportunizando também a participação popular informada.

Atente-se que uma vez ocorrido o dano ambiental, haverá uma constatação empírica de parte dos riscos resultantes daquele empreendimento operado naquela localidade específica, inclusive no que diz respeito à sua extensão e das comunidades que podem afetadas. Mesmo que a mineradora - cuja atividade foi suspensa ou cancelada - adote as medidas reputadas como necessárias para não repetição do referido dano, não se terá certeza absoluta de que ele não poderá acontecer novamente, inclusive na mesma extensão constatada no desastre que 
justificou a paralisação da atividade. Nesse caso a incerteza quanto aos riscos tem fundamento científico, ensejando a aplicação do princípio da precaução.

É sabido que não há desenvolvimento sem assunção de riscos e que a humanidade não teria avançado tanto sem enfrentá-los. No entanto, sendo esses riscos mensuráveis pela comunidade científica, mesmo que sua ocorrência/repetição seja incerta, abre-se campo para aplicação do Princípio da Precaução, que obriga o empreendedor a tomar todas as medidas de segurança cabíveis para evitar sua concretização. Para a constatação das medidas de segurança necessárias, pautando-se no Princípio da Precaução e no Estado Democrático de Direito, faz-se necessário ouvir a opinião das comunidades que podem ser afetadas em caso de dano ambiental.

Vale mencionar, assim, a perspectiva de Paulo de Bessa Antunes, em trecho no qual o autor defende a manutenção de atividades para as quais inexistem dados científicos suscitando riscos ao meio ambiente ou à saúde:

[...] the doubt about the harmful nature of a substance should not be interpreted as if there was no risk. However, risks have to be identifed based on scientifc information, with suitable protocols. The simple doubt - with no consistent base elements - should not be used as a basis for the paralyzation of activities without the necessary justifications ${ }^{21}[\ldots]$ (ANTUNES, 2016, p. 11)

Assim sendo, verificando-se que os riscos de danos socioambientais decorrentes da atividade minerária afetam uma área mais abrangente do que aquela constante nos Estudos Prévios de Impactos Ambientais que subsidiaram a concessão da licença, revela-se indispensável, em nome do Princípio da Precaução, promover redimensionamento da área impactada (área de influência), de modo a englobar toda a região efetivamente atingida. Devese, ademais, abrir espaço para a participação informada da população de toda a área impactada, tratando-se de requisito indispensável à legitimação do processo de licenciamento ambiental, em respeito ao Estado Democrático de Direito.

Como já visto, no caso de cancelamento da licença ambiental, caso a mineradora queira retomar suas atividades naquele mesmo local, deverá recomeçar todo o procedimento do licenciamento ambiental - licença prévia, licença de instalação e licença de operação -, inclusive no que tange à apresentação dos Estudos Prévios de Impactos Ambientais e de seu respectivo relatório. Nessa hipótese, ao se considerar a nova concepção de área impactada,

\footnotetext{
${ }^{21}[\ldots]$ a dúvida sobre a natureza nociva de uma substância não deve ser interpretada como se não houvesse riscos. Contudo, os riscos precisam identificados com base em informações científicas, com protocolos adequados. A simples dúvida - sem elementos de base consistentes - não deve ser utilizada como base para a paralisação de atividades sem as necessárias justificativas. [...]
} 
resultante do redimensionamento, deve-se assegurar à população de toda região efetivamente afetada o direito de participação, inclusive no que diz respeito à possibilidade de convocação de audiência pública.

Em se tratando de suspensão da licença operacional, antes de retomar suas atividades a mineradora deverá comprovar a adoção de medidas de precaução fundamentadas no redimensionamento da noção de área impactada. Ademais, devido à relevância do Princípio da Participação Popular no cenário de uma democracia deliberativa, mostra-se pertinente a oitiva da população das regiões efetivamente afetadas pelo desastre. Isso porque tal oportunidade não foi dada no momento da realização dos Estudos Prévios de Impactos Ambientais que possibilitaram a concessão da licença ambiental, nos quais não foi considerada a nova concepção de área impactada, capaz de ser afetada pela atividade minerária em questão.

\section{CONCLUSÃO}

$\mathrm{O}$ ordenamento jurídico brasileiro considera como significativamente impactante a atividade minerária, razão pela qual para a obtenção das licenças ambientais - licença prévia, licença de instalação e licença de operação -, deverá o empreendedor, com fundamento no princípio da precaução, apresentar Estudos Prévios de Impactos Ambientais e o consequente Relatório de Impactos Ambientais. Exige-se, ainda, a definição de uma estratégia de acompanhamento e monitoramento dos impactos efetivamente provocados pela atividade em razão de sua operação.

Diversas informações relevantes deverão compor o conteúdo dos referidos estudos, tal como a definição da área de influência geográfica do empreendimento - área impactada. Devese, portanto, definir as regiões que podem sofrer os impactos ambientais negativos decorrentes da mineração, de modo a possibilitar adoção de medidas de precaução que visem evitar a concretização de danos ambientais.

Para que a decisão do órgão ambiental licenciante seja válida e legítima sob o prisma do Estado Democrático de Direito e do princípio da cidadania - os quais não se limitam ao voto e às decisões tomadas pelo representante eleito -, ao confeccionar os Estudos Prévios de Impactos Ambientais será oportunizada à população da área impactada a participação informada, sendo possível formular opiniões e sugestões, além da convocação de audiência pública por 50 ou mais cidadãos.

Rev. de Direito e Sustentabilidade | e-ISSN: 2525-9687 | Maranhão | v. 3 | n. 2 | p. 52 - 70 | Jul/Dez. 2017. 
Tal participação se justifica pelo fato do direito fundamental ao meio ambiente equilibrado ser essencial à sadia qualidade de vida e também porque sua proteção é dever constitucionalmente imposto a toda coletividade. Ademais, verificando-se atos ou omissões que representem ameaça ou efetiva lesão meio ambiente, será possível ao cidadão propor ação popular, podendo se embasar nas informações constantes nos estudos.

Em caso de desastre ambiental envolvendo atividade minerária, torna-se relevante verificar se a área impactada coincide ou não com aquela definida anteriormente pelos Estudos Prévios de Impactos Ambientais. Caso se verifique a ocorrência de danos causados a regiões/comunidades não delimitadas pelos estudos, far-se-á necessário redimensionar a noção de área impactada para incluir todas as regiões efetivamente afetadas pelo empreendimento.

Diante da concretização de desastre ambiental, devido aos significativos danos ambientais e consequentes riscos sociais, poderá o Poder Público determinar, com fundamento no artigo 19 da Resolução CONAMA 237/97, a paralisação temporária ou permanente do empreendimento, por meio, respectivamente, da suspensão ou cancelamento da licença ambiental.

Na hipótese de cancelamento da licença, embora não seja comum a retomada da atividade na mesma localidade, a Lei não a proíbe. No entanto será necessário realizar novos Estudos Prévios de Impactos Ambientais, apresentando o respectivo relatório, reiniciando-se o processo de licenciamento ambiental destinado à obtenção da licença prévia, licença de instalação e licença de operação.

Em se tratando de suspensão da licença não se faz necessário promover novo processo de licenciamento ambiental, embora a mineradora seja obrigada a comprovar a regularização de seu empreendimento, demonstrando que foram tomadas medidas de precaução contra repetição de danos socioambientais.

Sob fundamento no princípio da precaução, tanto na hipótese de cancelamento quanto de suspensão da licença concedida à mineradora, a retomada das atividades dependerá da realização dos Estudos Prévios de Impactos Ambientais, os quais deverão, em razão da aplicação do princípio da precaução, considerar como área impactada toda a região efetivamente afetada pelos impactos ambientais decorrentes do desastre ambiental que justificou a paralisação da atividade.

Ademais, como a população das novas regiões enquadradas como áreas impactadas não teve a oportunidade de se manifestar no processo de licenciamento ambiental, faz-se 
necessário oportunizar-lhe o direito de participação informada, inclusive no que tange à convocação de audiência pública.

Ante todo o exposto, chega-se à conclusão de que em caso de suspensão ou cancelamento de licença concedida à mineradora, como consequência a desastre ambiental, a retomada das atividades dependerá do redimensionamento da noção de área impactada para abranger toda a região que sofreu efetivos impactos ambientais negativos. Será necessário garantir à respectiva população o exercício da cidadania mediante a participação informada, em coerência com o Estado Democrático de Direito, com o direito fundamental ao meio ambiente ecologicamente equilibrado e com o dever de proteção imposto aos indivíduos e à coletividade.

\section{REFERÊNCIAS}

ANTUNES, Paulo de Bessa. The Precautionary Principle in the Brazilian Environmental Law. Revista Veredas do Direito: Direito Ambiental e Desenvolvimento Sustentável, Belo Horizonte, v. 13, n. 27, p. 63-88, 2016. Disponível em:

http://www.domhelder.edu.br/revista/index.php/veredas/issue/view/41/showToc. Acesso em: 11 mai. 2017.

BECHARA, Erika. Licenciamento e compensação ambiental na Lei do Sistema Nacional das Unidades de Conservação (SNUC) / Erika Bechara. - São Paulo: Atlas, 2009.

BRASIL. Lei ${ }^{\circ}$ 6.938, de 31 ago. 1981. Dispõe sobre a Política Nacional do Meio Ambiente, seus fins e mecanismos de formulação e aplicação, e dá outras providências. Diário Oficial da União, Brasília, 02 set. 1981. Disponível em: http://www.planalto.gov.br/ccivil_03/leis/L6938.htm. Acesso em: 11 de maio de 2017.

BRASIL. Resolução CONAMA 001, de 23 de jan. 1986. Estabelece as definições, as responsabilidades, os critérios básicos e as diretrizes gerais para uso e a implementação da Avaliação de Impacto Ambiental como um dos instrumentos da Política Nacional do meio Ambiente. Diário Oficial da União, Brasília, 17 fev. 1986. Disponível em: http://www.mma.gov.br/port/conama/res/res86/res0186.html. Acesso em: 11 de maio de 2017.

BRASIL. Resolução CONAMA 009, de 03 de dez. 1987. Diário Oficial da União, Brasília, 05 jul. 1990. Disponível em: http://www.mma.gov.br/port/conama/res/res87/res0987.html. Acesso em: 11 de maio de 2017.

BRASIL. Constituição da República Federativa do Brasil de 1.988. Diário Oficial da União, Brasília, 05 out. 1988. Disponível em: http://www.planalto.gov.br/ccivil_03/constituicao/constituicao.htm Acesso em: 11 de maio de 2017. 
BRASIL. Resolução CONAMA 237, de 19 de dez. 1997. Diário Oficial da União, Brasília, 19 dez. 1997. Disponível em: http://www.mma.gov.br/port/conama/res/res86/res0186.html. Acesso em: 11 de maio de 2017.

BRASIL. Portaria DNPM 237, de 18 de out. 2001. Aprova as Normas Reguladoras de Mineração - NRM, de que trata o Art. 97 do Decreto-Lei no 227, de 28 de fevereiro de 1967. Diário Oficial da União, Brasília, 18 out. 2001. Disponível em: http://www.dnpm.gov.br/acesso-a-informacao/legislacao/portarias-do-diretor-geral-dodnpm/portarias-do-diretor-geral/portaria-no-237-em-18-10-2001-do-diretor-geral-dodnpm/view. Acesso em 11 de maio de 2017.

BRASIL. Lei 12.334, de 20 de set. 2010. Estabelece a Política Nacional de Segurança de Barragens destinadas à acumulação de água para quaisquer usos, à disposição final ou temporária de rejeitos e à acumulação de resíduos industriais, cria o Sistema Nacional de Informações sobre Segurança de Barragens e altera a redação do art. 35 da Lei no 9.433, de 8 de janeiro de 1997, e do art. 4ํㅡㄹ da Lei n⿳⺈ 9.984, de 17 de julho de 2000. Diário Oficial da União, Brasília, 20 set. 2010. Disponível em: http://www.planalto.gov.br/ccivil_03/_ato20072010/2010/lei/112334.htm. Acesso em: 11 de maio de 2017.

FARIAS, Talden. Licenciamento ambiental: aspectos teóricos e práticos / Talden Faroas; prefácio de Paulo Affonso Leme Machado. 4º edição. - Belo Horizonte: Fórum, 2013.

MACHADO, Paulo Affonso Leme. Direito ambiental brasileiro / Paulo Affonso Leme Machado - 24. ed. rev., ampl., e atual. - São Paulo : Malheiros, 2016.

MINAS GERAIS. Deliberação Normativa 127, de 27 de nov. 2008. Estabelece diretrizes e procedimentos para avaliação ambiental da fase de fechamento de mina. Diário do Executivo de Minas Gerais, Belo Horizonte, 29 nov. 2008. Disponível em:

http://www.siam.mg.gov.br/sla/download.pdf?idNorma=8732. Acesso em: 11 de maio de 2017.

ORGANIZAÇÃO DAS NAÇÕES UNIDAS. Declaração do Rio sobre Meio Ambiente e Desenvolvimento de 1992. ONU, Brasil, 1992. Disponível em:

http://www.onu.org.br/rio20/img/2012/01/rio92.pdf. Acesso em: 11 mai. 2017.

THOMÉ, Romeu; RIBEIRO, José Cláudio Junqueira. Community Participation in the Analysis of the Enrivornmental Impact Assessment. Revista Veredas do Direito: Direito Ambiental e Desenvolvimento Sustentável, Belo Horizonte, v. 13, n. 25, p. 69-91, 2016. Disponível em: http://www.domhelder.edu.br/revista/index.php/veredas/article/view/682. Acesso em: 11 mai. 2017.

TOLEDO, André de Paiva; RIBEIRO, José Cláudio Junqueira; THOMÉ, Romeu. Acidentes com Barragens de Rejeitos da Mineração e o Princípio da Prevenção: De Trento (Itália) a Mariana (Brasil). / André de Paiva Toledo, José Cláudio Junqueira Ribeiro, Romeu Thomé (Organizadores) ... [et. al.]. - 1. ed. - Rio de Janeiro: Lumen Juris, 2016 